\title{
Parametric Study of Automated Electrospark Deposition for Ni-Based Superalloys
}

\author{
The influence of seven process parameters on the deposition rate were studied \\ using a fractional factorial design of experiment
}

BY P. D. ENRIQUE, S. PETERKIN, AND N. Y. ZHOU

\begin{abstract}
Conventional electrospark deposition (ESD) processes used in industry are well suited to the coating and repair of small areas for the purpose of hardfacing, corrosion resistance, or dimensional restoration. Although significant advances have been made in the range of materials that can be processed, the comparatively slow deposition rate limits the potential applications of a traditional manually operated ESD process. In this study, an automated ESD system was demonstrated for the application of Ni-based superalloy (Inconel ${ }^{\circledR}$ 718) coatings on $\mathrm{Ni}$ - and Fe-based substrates. A preliminary study was used to determine the influence of process parameters on an automated system, with capacitance, voltage, electrode force, and electrode travel speed parameters chosen to provide higher deposition rates while maintaining high deposition quality. A comparison of Inconel 718 and 316L stainless steel substrates found that the influence of substrate composition on coating hardness and coating composition was limited to the first $40 \mu \mathrm{m}$. These results pave the way for ESD of largerarea coatings and longer-duration repairs without the need for human operators.
\end{abstract}

\section{KEYWORDS}

- Electrospark Deposition • Automation • Ni-Superalloy

- Inconel ${ }^{\circledR}$ • Stainless Steel

\section{Introduction}

A variety of industries, including nuclear, oil and gas, aerospace, metal processing, and chemical processing, benefit from reduced infrastructure costs by repairing or protecting Ni- and Fe-based components rather than fully replacing them. This is typically performed by depositing material to repair cracks and other surface defects or coating and recoating surfaces that experience degradation (Ref. 1), extending a component's service life. The deposition of Inconel ${ }^{\circledR} 718$ - a frequently used Ni-based superalloy with high strength and good corrosion resistance at elevated temperatures - has a long-studied history in both component repair and coating applications. Deposition of Inconel 718 and other Ni-superalloys has often been performed with laser directed-energy deposition (DED) (Refs. 2-6), thermal spray (Ref. 7), and cold spray (Refs. 8, 9). It has also been demonstrated for the joining, repair, and protective coating of similar and dissimilar substrates. For components particularly susceptible to thermal buildup during deposition, laser DED may be problematic. Although thermal spray and cold spray technologies result in lower heat input, issues with porosity and deposition/substrate bonding are common.

Electrospark deposition (ESD) is a micro arc-welding process commonly used for the repair and joining of sensitive, high-value parts as well as for interlayers and wear/ corrosion-resistant coatings (Refs. 10-14). The formation of a spark between an electrode (anode) and substrate (cathode) results in small droplets of electrode material transferring onto the substrate surface. With a combination of low heat input and high cooling rates (Ref. 15), ESD can produce fine-grained coatings and repairs with minimal damage to the substrate. However, the low material transfer rate limits the typically manual ESD process to the repair of small defects and coating of small areas.

Large-area repairs and coatings have the potential to be more economically feasible due to the development of versatile automated ESD systems. Additionally, factors such as electrode force and electrode travel speed can now be controlled, whereas they were left to the operator's discretion in manual ESD systems. An understanding of the impact of these factors in comparison to the more frequently controlled voltage, capacitance, and frequency factors can be used to obtain more uniform and higher-quality depositions.

Two applications of an automated ESD system were investigated in this study: the deposition of Inconel 718 to repair an Inconel 718 substrate and the deposition of Inconel 718 to coat a 316L stainless steel substrate. An experiment was constructed using a factorial design to identify ESD process parameters that provide good deposition rates, and the microstructure and properties of these coatings were characterized. 

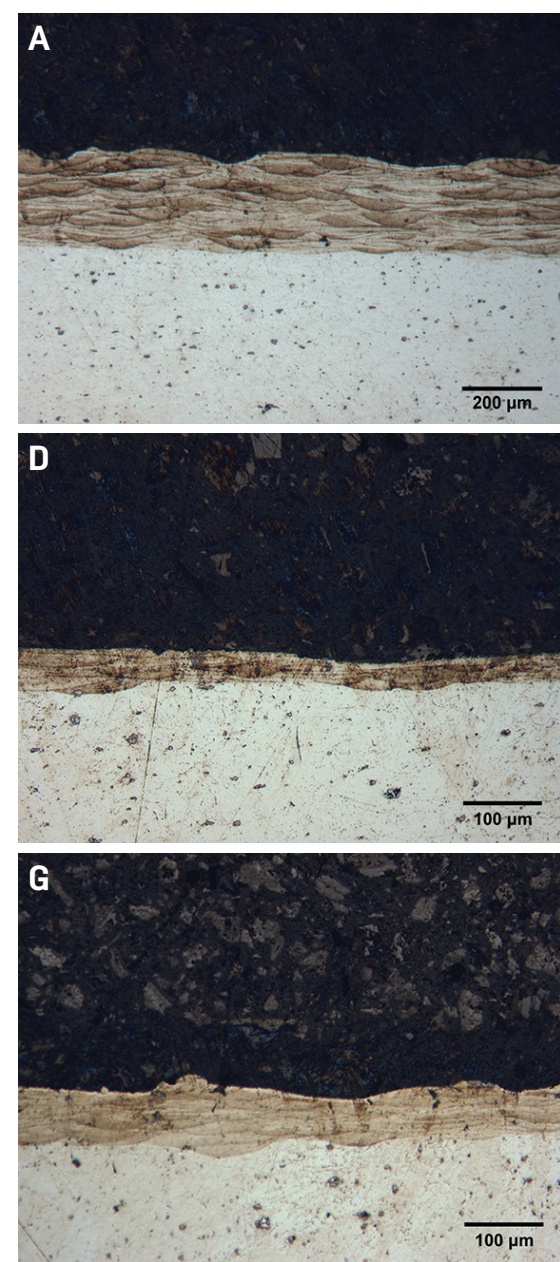
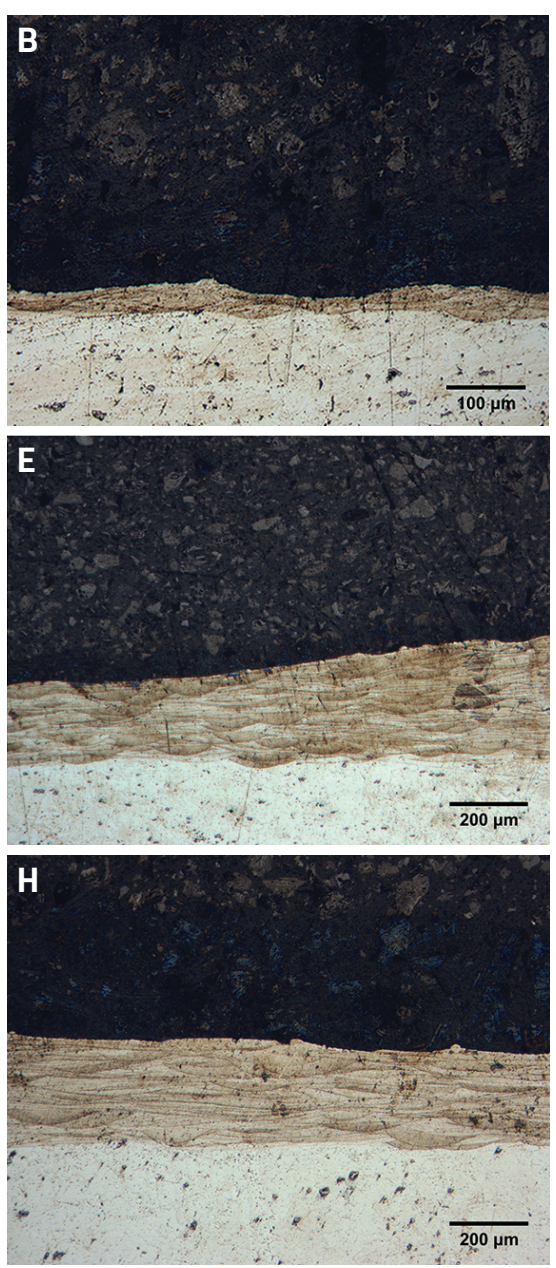
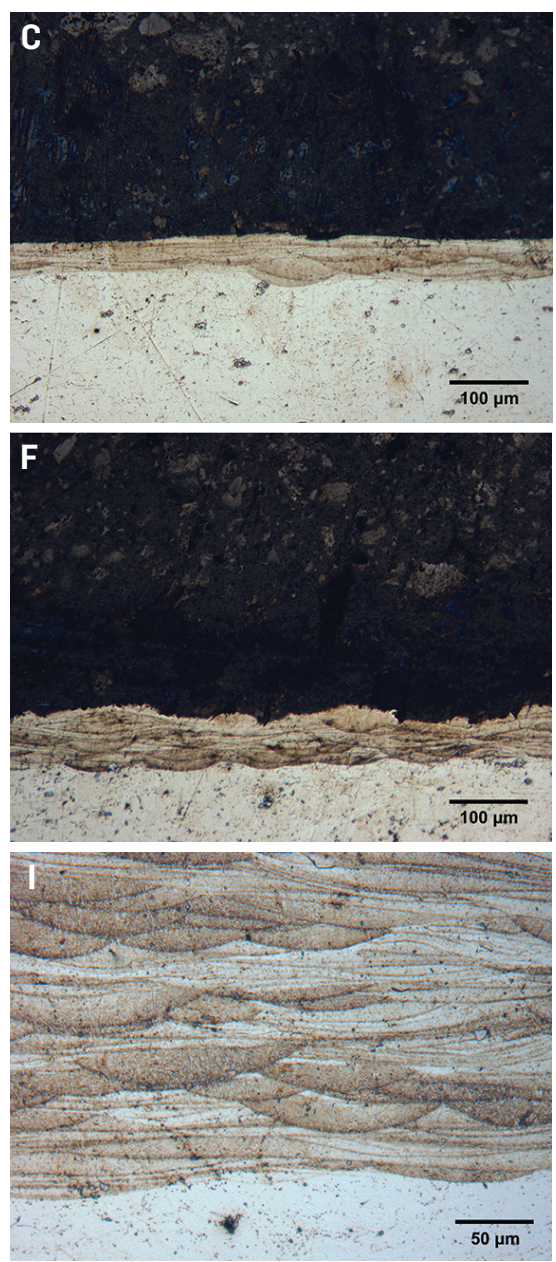

Fig. 1 - OM images of etched cross sections from Trials $1-8(\mathrm{~A}-\mathrm{H})$ and a higher magnification image of the layered droplet microstructure (I). Note the changes in scale between images.

\section{Materials and Methods}

\section{Process Parameters in Automated ESD}

The main electrical parameters driving the mass transfer mechanism for ESD include capacitance $(C)$, capacitor charge voltage $(V)$, and pulse frequency $(f)$ (Ref. 16). The ESD system used in this study operated in a direct current electrode positive configuration, although the system is capable of alternating current and electrode negative configurations. The ESD circuit charges the chosen capacitance to the set voltage level and uses a logic-driven thyristor circuit to control the discharge frequency. Contact between the electrode and substrate as well as some near-contact arcing events result in the discharge of the capacitor circuit with a high peak current, short duration pulse (Ref. 17). The capacitor charge voltage influences the maximum arc gap between the anode and cathode; a larger voltage, and consequently higher gap, results in greater ionization of gas atoms between the electrode and substrate. This creates more heat and increases the area of cathodic etching on the substrate. Higher capacitor voltages also result in higher peak current outputs from the capacitor circuits. The capacitance parameter has a linear effect on the energy discharged from the ESD circuit, with higher capacitance serving to broaden the current peak of the ESD discharge and increasing the duration of the arc. The Joule heating energy produced by the electrical ESD parameters is summarized by the total output energy $(E)$ in Equation 1 and power $(P)$ in Equation 2. The effect of the discharge frequency relates to the output power of the circuit, serving to control the heat

Table 1 - Chemical Composition (wt-\%) Determined by EDX

\begin{tabular}{cccccccccc} 
& $\mathrm{Ni}$ & $\mathrm{Cr}$ & $\mathrm{Nb}$ & $\mathrm{Mo}$ & $\mathrm{Ti}$ & $\mathrm{Al}$ & $\mathrm{Fe}$ & $\mathrm{Mn}$ & $\mathrm{Si}$ \\
\hline Substrate IN 718 & 54 & 19.7 & 3.3 & 2.6 & 1.1 & 0.3 & 19 & - & - \\
Electrode IN 718 & 53.7 & 19.2 & 3.8 & 2.8 & 1 & 0.3 & 19 & - & 0.2 \\
Substrate 316L SS & 10.2 & 17.8 & - & 3.9 & - & - & 66.1 & 1.4 & 0.6 \\
\hline
\end{tabular}



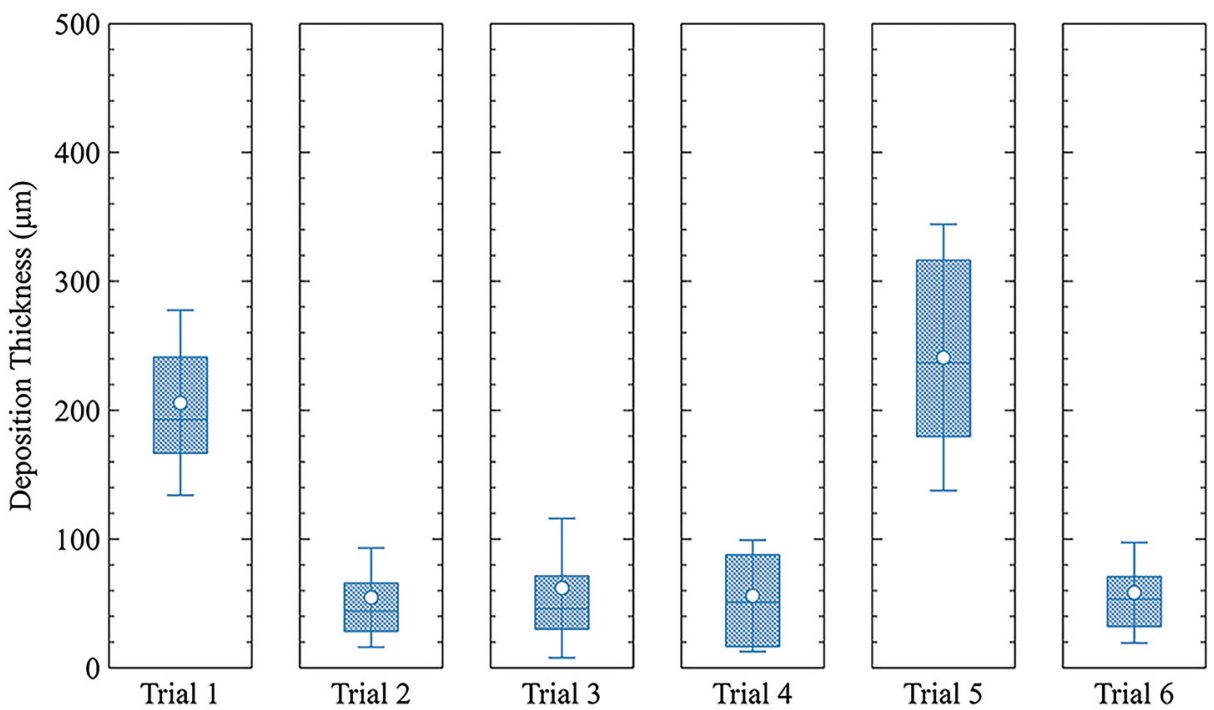

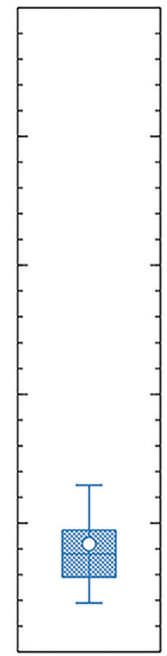

Trial 7

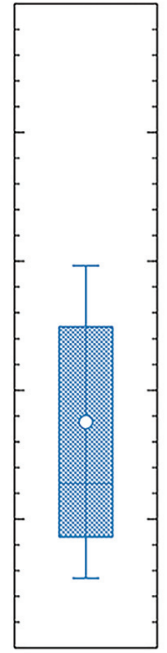

Trial 8

Fig. 2 - Deposition thickness for Inconel 718 on Inconel 718 with white dots showing the mean thickness, boxes showing $2^{\text {nd }}$ and $3^{\text {rd }}$ quartiles, and bars showing \pm one standard deviation.

buildup in the electrode and rate of material transfer. Because the electrode does not make constant contact with the substrate, an $\alpha$ term is introduced to obtain the actual frequency of capacitor discharge. Within the context of these trials, an average contact of $\alpha=0.96$ was achieved, which suggests that almost all the predicted power was delivered during the actual ESD process.

$$
\begin{aligned}
& E=1 / 2 C \times V^{2} \\
& P=E \times \alpha f=1 / 2 C \times V^{2} \times \alpha f
\end{aligned}
$$

Automated ESD systems are developed to minimize operator influence in the process. Power supply controls are used to set the capacitance, voltage, and frequency. Electrode motion is integrated into automated systems with accurate control over combinations of linear, rotating, and vibrating motion types that prevent the electrode from welding and sticking to the substrate. However, electrode compliance and electrodeto-substrate pressure control are the main concerns addressed with automated systems. Force, capacitor discharge, temperature, and visual feedback systems are often employed to maintain the optimal conditions for ESD coatings.

The automated ESD system functions as a coating head integrated with a motion system, such as a robot arm, CNC machine, or, in this case, a small gantry. The head is fitted with a fixed angle relative to the substrate plane, and a linear motor supports the weight of the head and provides compliance for the automated system. A load cell is fitted between the linear motor and the head, which is also influenced by the friction from the head bearings, a compression spring, and a neoprene damper. Thus, the force parameter is a measure of the compressive force applied by the linear motor when normalizing the tension forces of the weight of the head. The control system functions with hierarchical control loops, where the output is a motor movement command af- fecting the ESD head's position, which in turn affects the electrode position. First, the system determines if contact is made between the electrode and the substrate and capacitor discharge is occurring. If there is no contact, the unit will advance until the electrode makes an electrical contact with the substrate. Second, a closed-loop proportional integrative (PI) feedback system uses the force sensor input to output a movement command to maintain the set force parameter. Should the electrode lose contact with the workpiece due to a command from the PI control, or relief on the surface of the substrate, then the first control loop takes precedence. A simplified applied load equation is presented below, where the applied load $(F)$ is determined from the load at the load cell $\left(F_{L C}\right)$, the gravitational force on the coating head $(G)$, and the spring and damper effects $(S D)$.

$$
F=F_{L C}-G \times S D
$$

\section{Materials and Characterization}

The 3.2-mm-diameter electrode used for ESD was made of Inconel 718, with the composition listed in Table 1 . The 10-mm-thick, $25 \times 25$-mm substrates used for this study included solution-annealed Inconel 718 and 316L stainless steel, the compositions of which are also listed in Table 1. Cross sections of the coating tracks were made using a Struers Accutom-50 precision saw. To prepare samples for analysis, cross sections were hot mounted in a conductive resin, ground with a series of silicon carbide grinding papers (400, 600, 800, and 1200 grit), and then polished using an alumina slurry with $1-\mu \mathrm{m}$ particle size. Select samples were etched with inverted glyceregia $\left(\mathrm{HCl}: \mathrm{HNO}_{3}\right.$ :Glycerol in a 5:1:1 ratio) for approximately $75 \mathrm{~s}$.

Characterization of cross-sectioned samples was performed using an Oxford BX51M optical microscope (OM). Higher magnification images were obtained with a Zeiss UltraPlus 


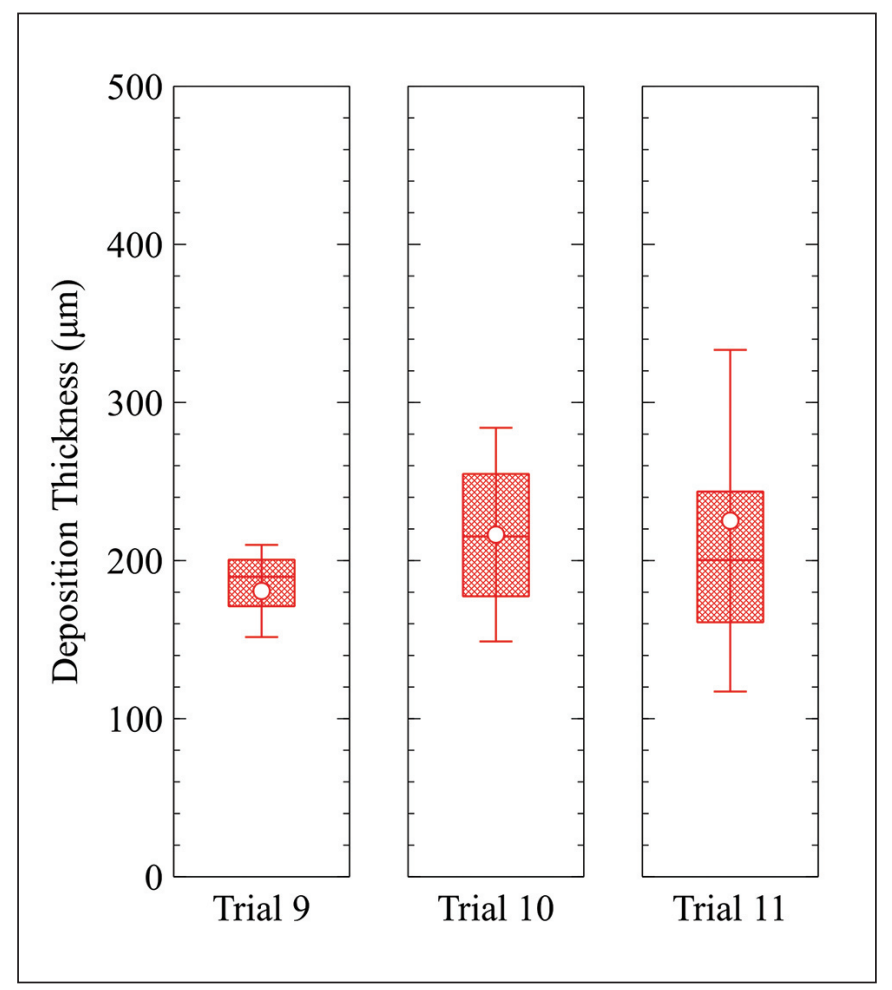

Fig. 3 - Deposition thickness for Inconel 718 on 316L stainless steel with white dots showing the mean thickness, boxes showing $2^{\text {nd }}$ and $3^{\text {rd }}$ quartiles, and bars showing \pm one standard deviation.

scanning electron microscope (SEM) and an AMETEK EDAX Apollo XL energy-dispersive $\mathrm{x}$-ray spectroscopy (EDX) attachment. Hardness measurements were performed on a Wolpert Wilson ${ }^{\circledR} 402$ MVD micro Vickers hardness tester using a load of $0.1 \mathrm{kgf}$. The measurement of coating thickness and quantity of defects was done using Image $\mathrm{J}$ on the OM cross section images. Analysis of the obtained data was performed using Develve, jamovi, and Veusz software.

\section{Experimental Design}

Previous studies on the manual ESD of Inconel 718 have identified electrical parameters in which high-quality depositions are achievable (Refs. 18-20), and these studies were used as the basis for parameter selection on the newly developed automated system. The response variable of interest in this study was the deposition thickness, which is related to the deposition rate and is used to address an industry need for faster ESD process times and thicker coatings. The quantity of defects within the coatings were also measured to confirm that the coatings created with the chosen parameters are suitable for industries where high coating quality is necessary.

A resolution III fractional factorial design of experiment was chosen to identify which process parameters had an influence on the final deposition thickness. A Huys Industries automated low-energy welding system with a 4100automation head controller and a 6350-automation integrated universal ESD power supply was used. Parameters for the deposition of Inconel 718 on Inconel 718 are listed in Table 2 and parameters for Inconel 718 deposited on 316L stainless steel are listed in Table 3. All depositions were performed using coaxially delivered 5.0-grade argon shielding gas. The electrode angle was kept constant at 45 deg, and the vibration on/off parameter dictated if the electrode was driven in a linear motion by a $2.5-\mathrm{mm}$-offset, $33-\mathrm{g}$ mass rotating at $3500 \mathrm{rpm}$. Deposition time was kept constant at $15 \mathrm{~min}$ per track, and three $10-\mathrm{mm}$ tracks were made for each trial. A unidirectional scan pattern was used with the electrode lifted from the substrate at the end of the track and returned to the substrate at the beginning. These tracks were then cross sectioned along their long axis for analysis, and a minimum of 150 measurements of coating thickness were made for each trial. Low and high parameters for each of the factors were 70 and $100 \mathrm{~V}$ for the voltage, 60 and $100 \mu \mathrm{F}$ for the capacitance, 70 and 100 $\mathrm{Hz}$ for the frequency, 440 and $940 \mathrm{rpm}$ for the rotation speed, 100 and $300 \mathrm{~mm} / \mathrm{min}$ for the travel speed, off and on for the vibration, and 0.2 and $2.3 \mathrm{~N}$ for the force.
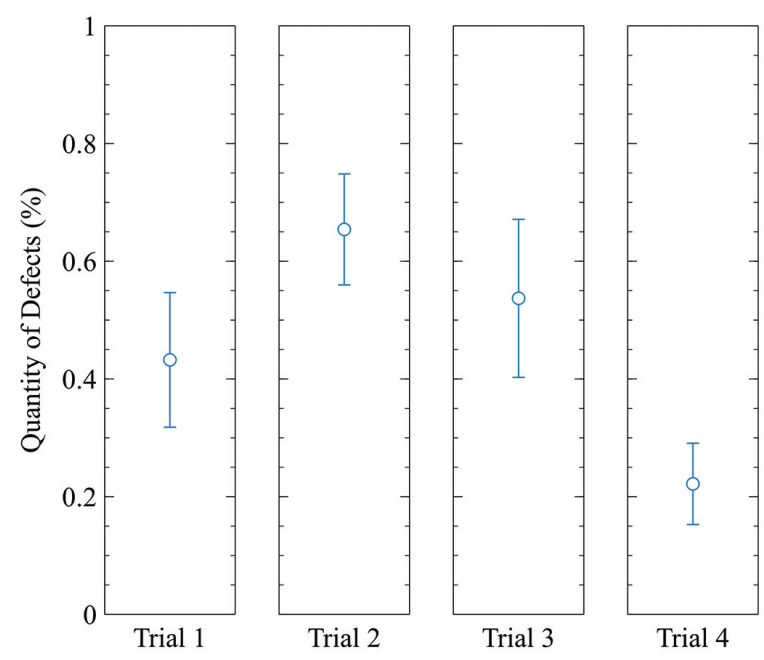

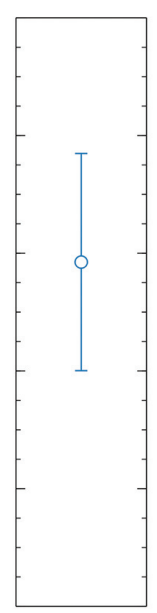

Trial 5

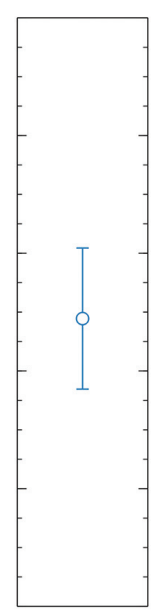

Trial 6

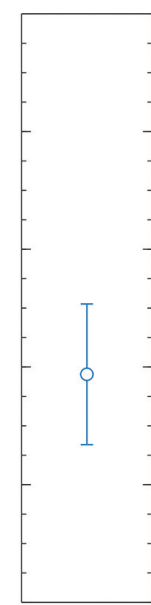

Trial 7

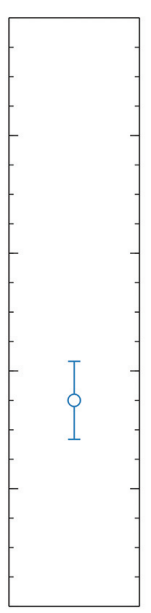

Trial 8

Fig. 4-Quantity of defects for initial trials with white dots showing the mean defect area and bars showing \pm one standard error. 
Table 2 - Trial Parameters for Deposition of Inconel 718 on Inconel 718

\begin{tabular}{|c|c|c|c|c|c|c|c|}
\hline Trial & Force $(\mathrm{N})$ & Travel Speed (mm/min) & Vibration & $\begin{array}{c}\text { Factor } \\
\text { Capacitance }(\mu \mathrm{F})\end{array}$ & Frequency $(\mathrm{Hz})$ & Voltage $(\mathrm{V})$ & Rotation Speed (rpm) \\
\hline 1 & 0.2 & 100 & On & 100 & 70 & 100 & 440 \\
\hline 2 & 0.2 & 100 & On & 60 & 100 & 70 & 940 \\
\hline 4 & 0.2 & 300 & Off & 60 & 100 & 100 & 440 \\
\hline 5 & 2.3 & 100 & Off & 100 & 100 & 100 & 940 \\
\hline 6 & 2.3 & 100 & Off & 60 & 70 & 70 & 440 \\
\hline
\end{tabular}

Table 3 - Trial Parameters for Deposition of Inconel 718 on 316L Stainless Steel

\begin{tabular}{|c|c|c|c|c|c|c|c|}
\hline Trial & Force $(\mathrm{N})$ & Travel Speed (mm/min) & Vibration & $\begin{array}{r}\text { Factor } \\
\text { Capacitance }(\mu \mathrm{F})\end{array}$ & Frequency $(\mathrm{Hz})$ & Voltage $(\mathrm{V})$ & Rotation Speed (\%) \\
\hline 9 & 2.3 & 100 & On & 100 & 178 & 75 & 100 \\
\hline 10 & 2.3 & 100 & On & 100 & 100 & 100 & 100 \\
\hline
\end{tabular}

\section{Results}

The optical images in Fig. 1A-H show representative cross sections of the deposition and substrate according to Trials 1-8 in Table 2. Figure 1I displays at higher magnification the typical microstructure features that are common in ESD coatings. The etchant made visible droplets, which were transferred during ESD and were repeatedly layered to build up the coating.

Deposition thickness data obtained from cross sections is presented in Fig. 2. Trials 1, 5, and 8 all displayed a significant buildup of deposited material and full coverage along the deposition track. Trials 2, 3, 4, and 6 were noticeably thinner with some regions having no deposition coverage. On the other hand, Trial 7 showed a thin but more consistent coverage along the entire cross section. Deposition thickness data from Trials 9, 10, and 11 are shown in Fig. 3, with all samples displaying a significant buildup of deposited material comparable to Trials 1,5 , and 8.

Measurements of defect quantity, however, did not show notable differences between trials, with all samples having an average area of defects below $1 \%$ - Fig. 4 . This is similar to previous studies, which used comparable parameters on a manually operated ESD system to obtain good quality depositions with few defects (Refs. 18-20). The main type of defect detected in this study is also similar to those previously reported, consisting primarily of Aland Ti-rich oxides (Fig. 5) with small quantities of $\mathrm{Cr}, \mathrm{Nb}$, and Mo. The high standard free energy of formation for $\mathrm{Al}$ and $\mathrm{Ti}$ oxides explains their prevalence in this phase (Ref. 21), with aggregation of these elements attributed to diffusion while the transferred material was at elevated temperatures. The extent of diffusion and the resulting quantity of these phases has been shown to decrease with the use of lower capacitance, voltage, or frequency, all of which reduce the overall heat input (Ref. 22). A comparison of the chosen electrical parameters in Table 1 to those stud-
Table 4 - Coefficient Statistics for Model in Equation 4

\begin{tabular}{cccc} 
& Standard Error & $\mathrm{T}$ & Pooled $\mathrm{p}$-values \\
\hline Constant & 76.836 & -3.863 & 0.003 \\
Force (F) & 9.910 & 1.932 & 0.080 \\
Travel Speed (TS) & 0.104 & -2.171 & 0.053 \\
Capacitance (C) & 0.520 & 3.144 & 0.009 \\
Voltage (V) & 0.694 & 5.119 & $<0.001$ \\
\hline
\end{tabular}

ied in Ref. 22 suggests that an area of defects below $1 \%$ is not unexpected.

For applications that require further defect reductions, an increase in shielding gas flow rate or the use of multiple shielding gas sources or a glovebox enclosure are expected to lower the quantity of oxide inclusions that form. Very few gas pores were identified, while lack of fusion defects and cracks were mainly observed at the track ends. This is attributed to changes in the arc gap at locations where the electrode was brought into contact or removed from the substrate.

For the deposition of Inconel 718 on 316L stainless steel, the use of an SEM backscatter detector (Fig. 6) showed a lighter coating - indicative of a material with higher atomic number - and a dark substrate. In between was the presence of a region with an intermediate shade. This suggests that a mixing zone (MZ) was formed due to substrate melting, which acted to dilute the Inconel 718 transferred from the electrode. The use of EDX confirmed that the composition of the MZ was between that of Inconel 718 and 316L stainless steel with respect to the $\mathrm{Ni}$ and Fe content and was approximately $40 \mu \mathrm{m}$ in size.

The effect of the MZ on hardness is shown in Fig. 7A, with a noticeably softer region within the coating that is not present in the case of Inconel 718 deposited on Inconel 718 (Fig. 7B). Deposited material beyond the first $40 \mu \mathrm{m}$ displayed the expected hardness of Inconel 718. Both depositions shown in Fig. 7 resulted in some hardening of the substrate, limited to approximately $100 \mu \mathrm{m}$. 

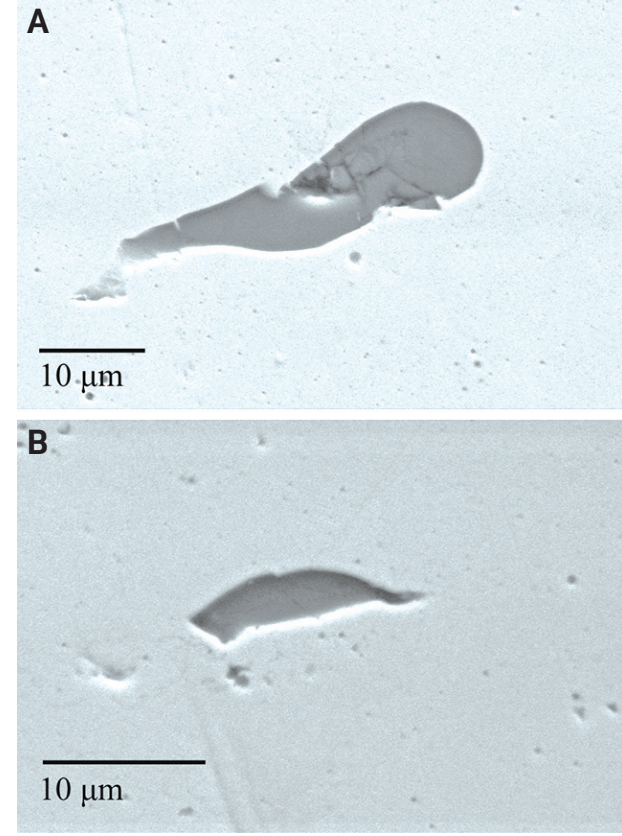
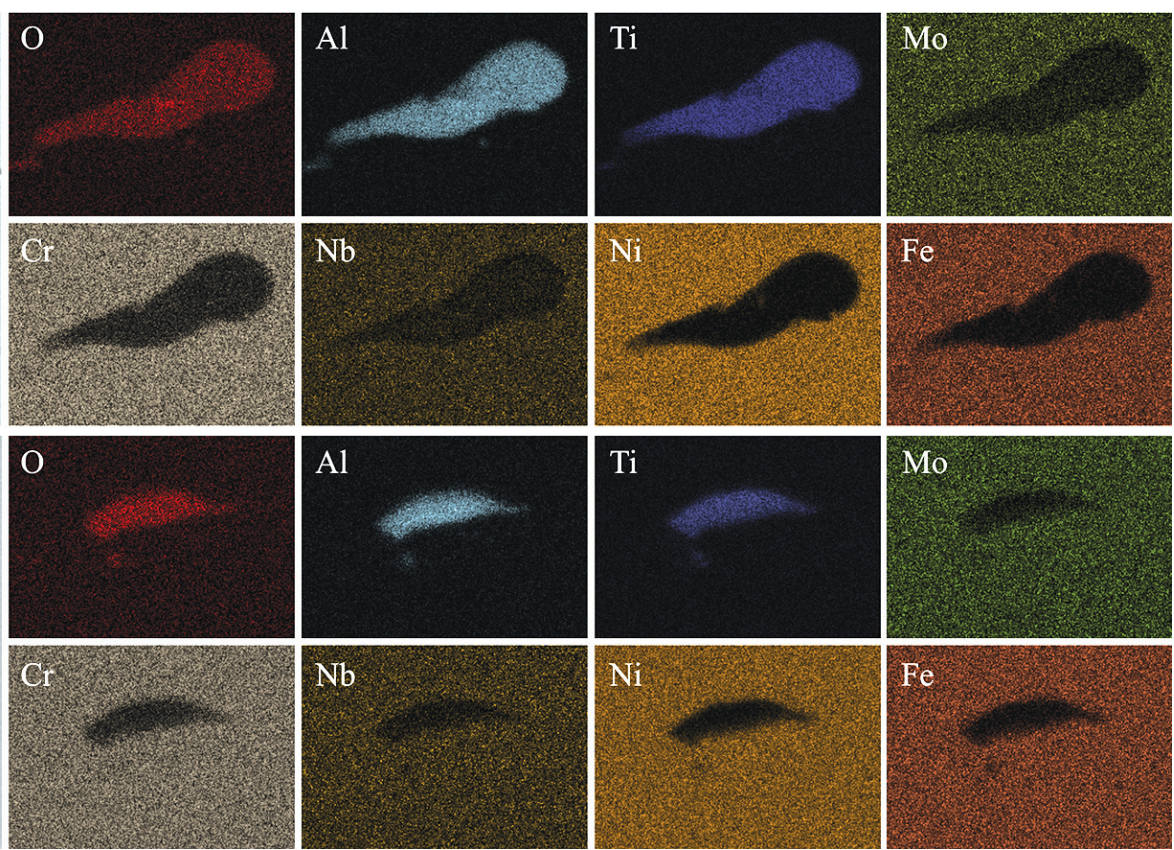

Fig. 5 - SEM images and their respective EDX maps. A - An Al- and Ti-rich cracked oxide defect in ESD-processed Inconel 718; $B-$ a smaller intact oxide defect with similar composition.

\section{Discussion}

\section{Influence of Process Parameters on Thickness}

An analysis of variance (ANOVA) method was used to determine whether a statistically significant difference in the mean deposition thickness existed. The nonpooled p-values are shown in Fig. 8 and were used to discard factors clearly did not provide a significant influence on deposition thickness in the chosen process parameter range. These included the rotation speed of the electrode $(p=0.146)$, frequency ( $p$ $=0.593)$, and electrode vibration $(p=0.214)$. Once these factors were pooled, the new $\mathrm{p}$-values were compared. With a threshold $\mathrm{p}$-value of 0.1 indicating significance, voltage $(\mathrm{p}$ $<0.001)$, capacitance $(\mathrm{p}=0.009)$, travel speed $(\mathrm{p}=0.053)$, and force $(\mathrm{p}=0.08)$ factors were significant in the range studied. These four factors also provided a good balance between predictive ability and complexity for the regression analysis, obtaining a predictive model with an adjusted $\mathrm{R}^{2}$ value of 0.73 that dropped to 0.60 when travel speed and force were removed, but only increased to 0.77 when rotation speed, frequency, and electrode vibration were included. The significance of the parameters and their effect on the response variable in the model can be seen in Fig. 8 and Table 4. Voltage had a noticeably larger effect on the deposi- tion thickness when varying from the low to high setting $(106.5 \mu \mathrm{m})$ when compared to the capacitance $(65.4 \mu \mathrm{m})$, travel speed $(45.2 \mu \mathrm{m})$, and force $(40.2 \mu \mathrm{m})$.

Based on these results, Equation 4 can be expected to predict deposition thickness $(D)$ in units of $\mu \mathrm{m}$, where $V$ is the voltage in volts, $C$ is capacitance in $\mu \mathrm{F}$, TS is the travel speed in $\mathrm{mm} / \mathrm{min}$, and $F$ is the force in newtons. As shown in Table $5,80 \%$ of the variability in deposition thickness is explained by these four factors.

$$
D=3.55 V+1.64 C-0.23 T S+19.15 F-296.82
$$

The electrospark deposition process has three primary electrical parameters: voltage, capacitance, and frequency. An increase in both voltage and capacitance parameters are expected to increase the ESD spark energy, according to the equation for stored energy in a capacitor (Equation 1). Greater spark energy has been shown to increase the deposition rate and mass transfer quantity (Ref. 23). This can be attributed to higher temperatures and greater melting of the electrode. The influence of voltage is greater than that of capacitance (Ref. 24), which can be attributed to the square dependence of voltage - and only linear dependence of capacitance - on energy output. The voltage further affects the arc gap of the ESD process (Ref. 24) and the current peak of the ESD discharge. The capacitance increases the net energy and broadens the current peak, resulting in a longer arc duration.

Table 5 - Analysis of Variance Statistics for Model in Equation 4

\begin{tabular}{lccccccc} 
& df & Sum of Squares & Mean Square & F & p & $\mathrm{R}^{2}$ & Adj. $\mathrm{R}^{2}$ \\
\hline Model & 4 & 7714713 & 19286.78 & 11.13 & $<0.01$ & 0.80 \\
Error & 11 & 19055.3 & 1732.3 & - & - & - \\
Total & 15 & 96202.43 & - & - & - & - \\
\hline
\end{tabular}




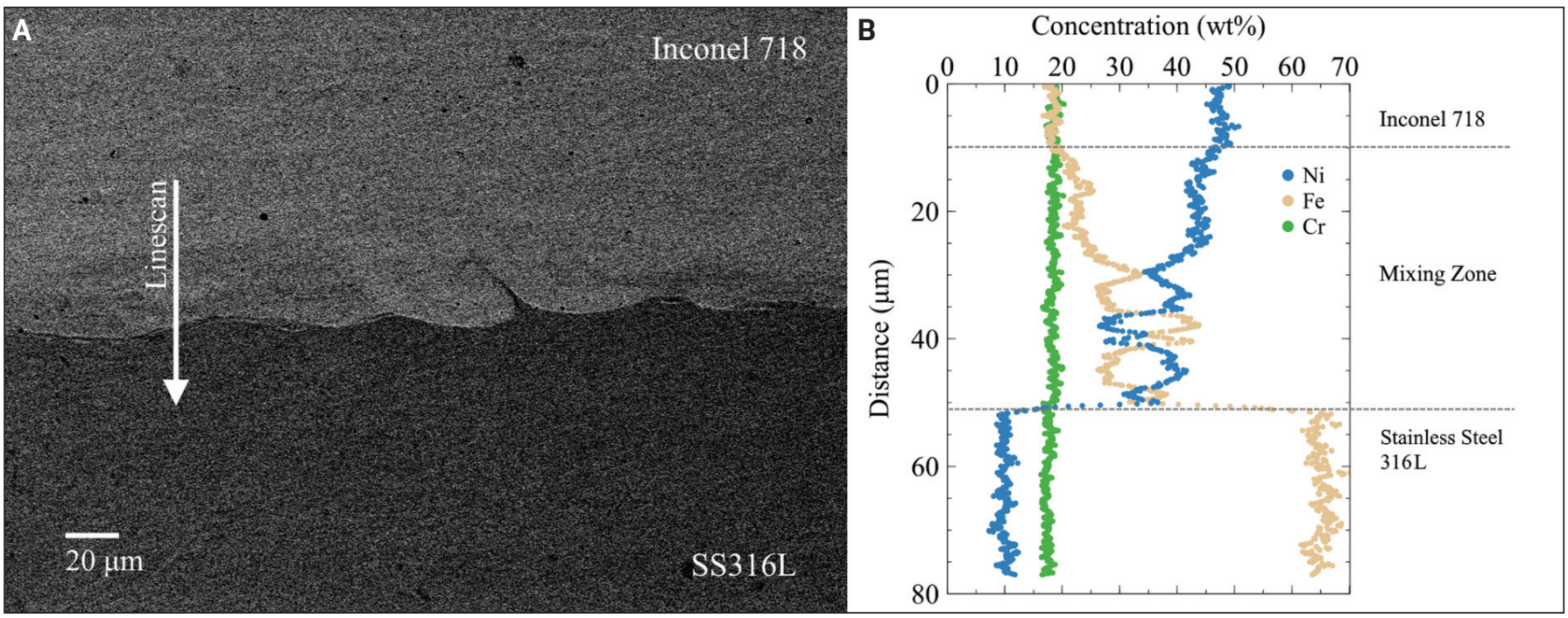

Fig. 6-A - SEM backscatter detector image of Inconel 718 deposited on 316L stainless steel; B - EDX composition results along the line indicated in $A$.
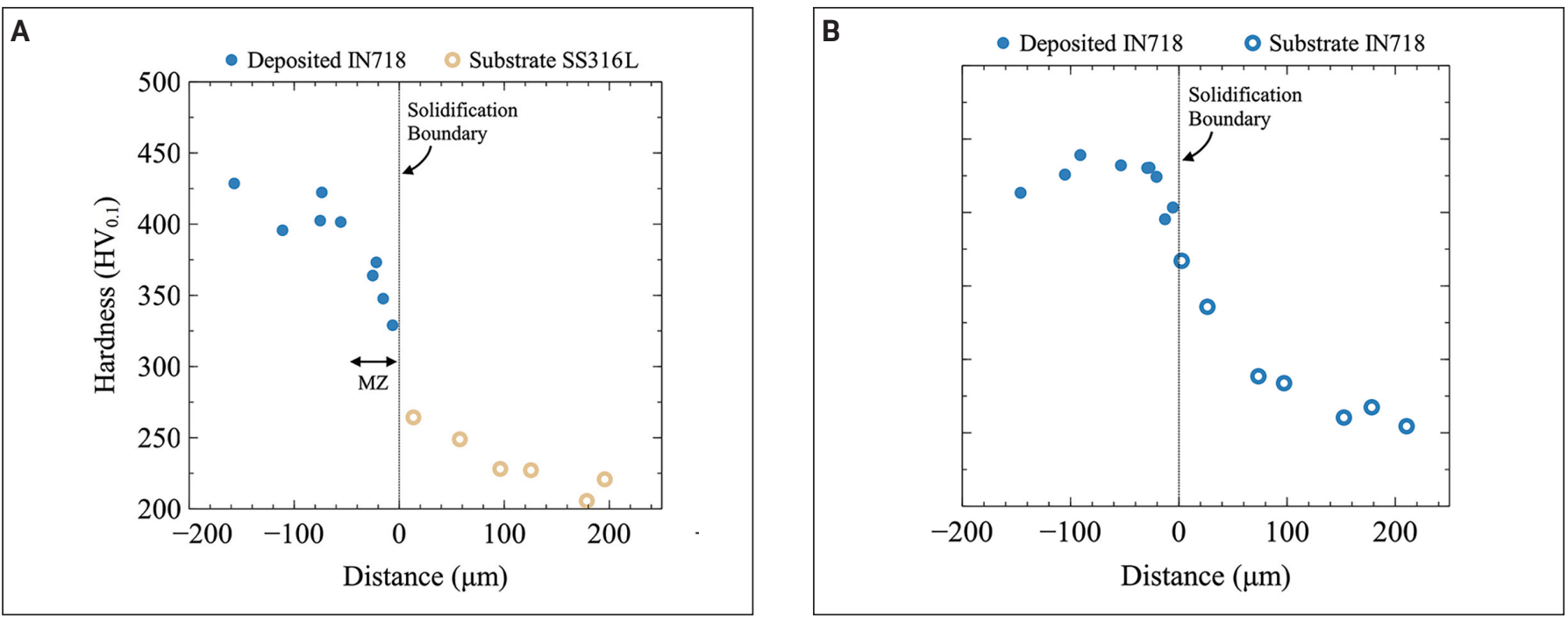

Fig. 7 - Microhardness measurements. A - Inconel 718 (IN718) deposited on 316L stainless steel (SS316L); B - Inconel 718 deposited on Inconel 718.

These findings are clearly seen in Fig. 8 and reflected in Equation 4, where voltage and capacitance have a positive relationship with the deposition thickness. An increase in the frequency of electrical discharge is also expected to increase the deposition rate with a greater number of mass transfer events. A secondary effect of an increase in the frequency parameter is greater heat buildup in both the electrode and substrate (Ref. 25), attributed to an increase in heat generation without an equivalent increase in the rate of heat dissipation. However, the present study found the chosen frequency range typically used for deposition of Inconel 718 had no significant effect on deposition thickness. This agrees with a previous study that found no difference in substrate mass change when varying frequency from 55 to $90 \mathrm{~Hz}$ (Ref. 25), although another study that investigated higher frequencies from 200 $\mathrm{Hz}$ to $5 \mathrm{kHz}$ reported a positive relation between frequency and deposition thickness (Ref. 26).

With respect to the mechanical parameters, an increased travel speed is expected to decrease material transfer due to faster heat dissipation (Ref. 25). As the electrode moves more quickly to a lower temperature region of the substrate, there is less heat buildup and less material melting than would be expected from repeated discharges in one localized area. This is reflected in Equation 4, with a negative relationship between the travel speed and deposition thickness.

Table 6 - One-Way Welch's ANOVA for the Effect of Vibration on Force and the Standard Deviation of Force

\begin{tabular}{|c|c|c|c|c|}
\hline & \multicolumn{2}{|c|}{ Group Descriptives } & \multirow[b]{2}{*}{ SD } & \multirow{2}{*}{$\begin{array}{c}\text { One-Way ANOVA } \\
\text { p-value }\end{array}$} \\
\hline & Vibration Factor & Mean & & \\
\hline \multirow[t]{2}{*}{ Force } & Off & 1.37 & 1.4733 & \\
\hline & On & 1.375 & 1.337 & 0.996 \\
\hline \multirow{2}{*}{$\begin{array}{l}\text { Std. Dev. } \\
\text { of Force }\end{array}$} & Off & 0.343 & 0.0768 & \\
\hline & On & 0.762 & 0.0883 & $<0.001$ \\
\hline
\end{tabular}




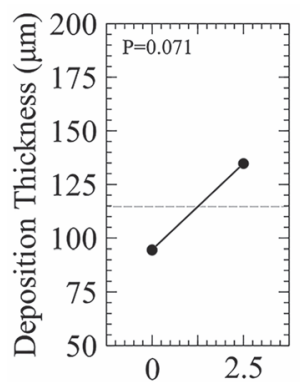

Force $(\mathrm{N})$

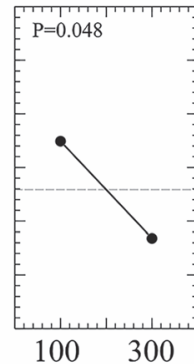

Travel Speed (mm/min)

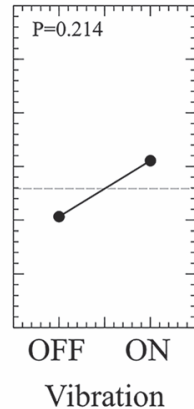

Vibration

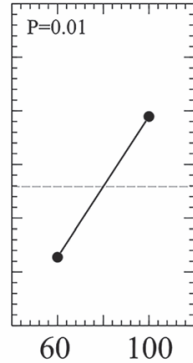

Capacitance

$(\mu \mathrm{F})$

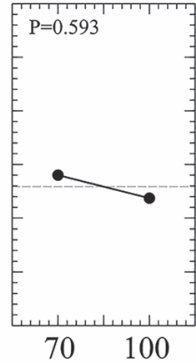

Frequency $(\mathrm{Hz})$

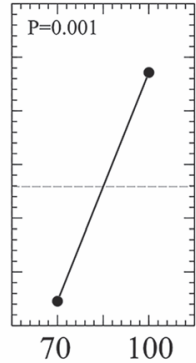

Voltage (V)

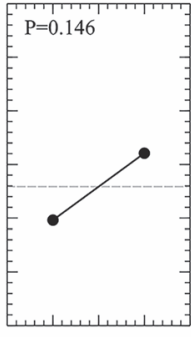

440940

Rotation Speed

(rpm)

Fig. 8 - Mean of means plots for the main factors with non-pooled p-values displayed.

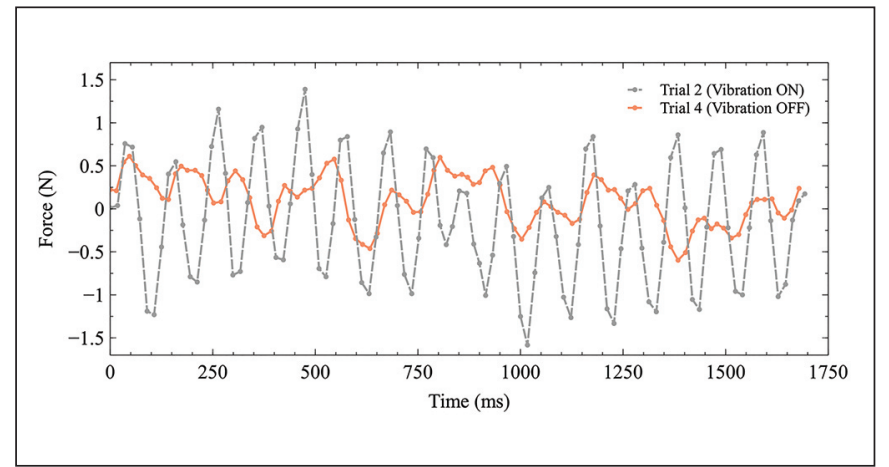

Fig. 9-Load cell readings from Trial 2 and Trial 4.

The distance between the electrode and substrate - controlled by the force parameter - may change the electrical discharge and mass transfer mechanism. Lower forces that result in larger discharge gaps have shown increased mass gain on the substrate (Refs. 25, 27), with contradicting results as to whether an increase in force increases or decreases the substrate temperature (Refs. 25,28 ). However, in the current study, an unexpected relationship was obtained; a greater force applied on the substrate by the electrode resulted in a thicker deposition. This can be attributed to the ESD process being effective within a narrow band of applied electrode pressure, where no contact prevented the ESD circuit from discharging, and too high of a pressure resulted in a short circuit contact and no sparking event. Other mechanical parameters, such as electrode vibration and electrode rotation speed, which are used to prevent fusion of the electrode to the substrate, did not measurably influence the deposition thickness.

Some limitations to the study and findings are worth identifying. As is typically the case with these experiment designs, it is not prudent to extrapolate Equation 4 and the relationships in Fig. 8 beyond the parameter ranges studied. This is because depositions created with high process parameters were shown to have a maximum thickness, after which erosion occured (Ref. 29). The existence of a maximum deposition thickness - or equivalently, a maximum deposition time - was attributed to thermal-fatigueinduced erosion of the workpiece that became more pronounced as the deposition thickness increased (Ref. 30).
Measurements captured during ESD of the load cell supporting the coating head revealed that electrode vibration may influence the electrode force. An example is shown in Fig. 9, where load cell readings from Trial 2 with electrode vibration showed higher deviation from the set point than those of Trial 4 without electrode vibration. A one-way Welch's ANOVA of Trials 1-8 (Table 6) indicates vibration had no significant influence on the average force $(p=0.996)$. The force feedback mechanism was able to maintain the desired average setpoint regardless of the vibration setting. However, vibration did significantly affect the standard deviation of the force ( $\mathrm{p}<$ 0.001), confirming the observation in Fig. 9. A greater deviation in force increases and decreases the distance between the electrode and the substrate, leading to potential changes in the mass transfer mechanism. However, vibration or force $\times$ vibration was not found to influence the deposition thickness with statistical significance within the parameter range investigated. Qualitative analysis of the overall visual appearance of the coatings did demonstrate an effect of the vibration $\times$ force interaction on the localized buildups and overall surface roughness of the coatings. Increased surface roughness was shown in literature to not influence the average coating thickness or deposition rate (Ref. 31), although a reduced roughness is beneficial for the formation of uniform coatings that require less post-processing and offer greater protection to the underlying substrate.

\section{Model Validation and Extension to 316L Stainless Steel Substrates}

A comparison of predicted and actual thicknesses based on Equation 4 are shown in Fig. $10 \mathrm{~A}$ to validate the suitability of the obtained model. The closer the values are to the 45 deg line, the more accurate the thickness prediction. Prediction quality is also quantified through the standardized residuals in Fig. 10B, with positive residuals indicating a prediction that was higher than the actual value and negative residuals indicating a prediction that was lower.

The ability of Equation 4 to predict deposition thickness for Inconel 718 on Inconel 718 was consistent across the entire studied range, with similar residuals regardless of the predicted thickness. The ability to predict thickness for the deposition of Inconel 718 on 316L stainless steel was also quite good, 

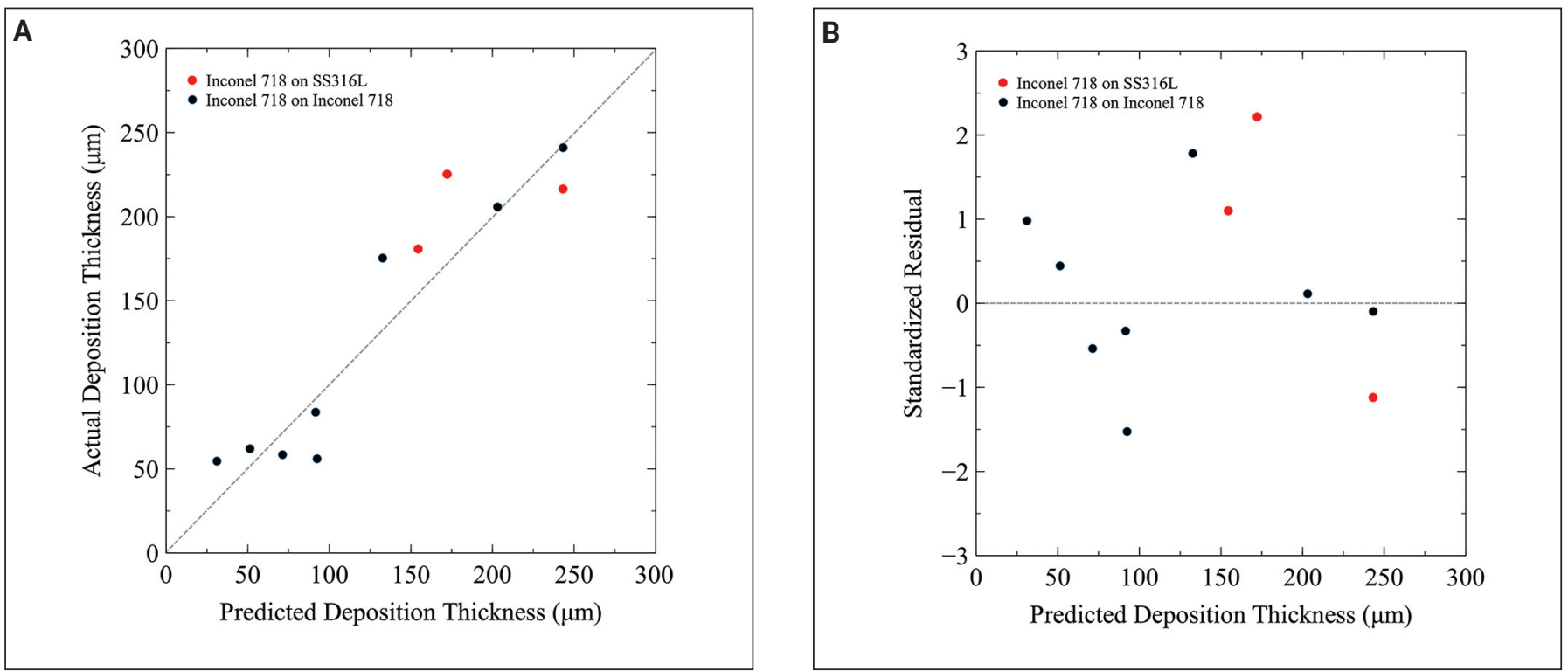

Fig. $10-A-$ Comparison of predicted and actual deposition thickness; $B$ - the standardized residual of the predicted deposition thickness.

with similar residuals to the initial trials. Overall, $91 \%$ of the predicted deposition thicknesses fell within two standardized residuals of the actual thicknesses. This was close to the expected result of $95 \%$ assuming a normal distribution, especially considering the small sample size of 11 data points. This suggests that the model is useful for predicting the deposition of Inconel 718 on nickel- and steel-based substrates. The physical reason for this is attributed to the small MZ identified in Fig. 6, where the effect of the substrate material on the deposition was limited to the first few layers.

Within these layers, substrate melting was occurring, and substrate erosion rates will differ depending on the substrate material. However, after a certain deposition thickness, the deposited material and exposed top layer can be considered effectively the same material, and the deposition rates would be similar for thicker coatings. Mechanical properties of these coatings are also expected to be similar without significant influence from the substrate. Microhardness results in Fig. 7A show that a reduction in hardness of the coating occured within the $40 \mu \mathrm{m} \mathrm{MZ} \mathrm{between} \mathrm{Inconel} 718$ and SS316L, comparable to results previously shown in literature for other material combinations (Refs. 29, 30, 32). However, a comparison of Fig. $7 \mathrm{~A}$ and $\mathrm{B}$ shows that the coating hardness of the upper layers was similar regardless of the substrate composition. The limited dilution is promising for the dissimilar coating of Fe-based parts with Ni-based superalloys, which can provide improved surface properties at a lower cost than using a fully Ni-based superalloy part.

\section{Conclusions}

The use of an automated ESD system for deposition of Inconel 718 on similar (Inconel 718) and dissimilar (316L stainless steel) substrates was demonstrated. The influence of seven process parameters on the deposition rate were studied using a fractional factorial design of experiment to make the coating of larger areas more feasible. The chosen range of process parameters resulted in coatings with an average thickness of as little as $50 \mu \mathrm{m}$ to an average thickness of $240 \mu \mathrm{m}$, with four process parameters identified as the most significant contributors to the variation in thickness. The influence of Ni- or Fe-based substrates on the deposition rate and coating properties were also investigated, with the regression model created for deposition on Inconel 718 also effective at predicting deposition thickness on 316L stainless steel. The following conclusions were drawn from the current study:

1) Of the seven process parameters studied, two electrical factors (voltage and capacitance) and two mechanical factors (force and travel speed) had a significant effect ( $\mathrm{p}<0.1$ ) on the deposition rate. Voltage, capacitance, and force were all found to be positively correlated with the deposition rate, while a higher travel speed resulted in thinner coatings. Three factors (electrode rotation, electrode vibration, and frequency) were not statistically significant within the parameter ranges investigated.

2) Electrode vibration was found to affect the standard deviation of the measured force. This has implications for coating roughness but did not influence the deposition rate.

3) A relationship between the significant process parameters and deposition rate was successfully used to identify parameters that can more quickly produce Inconel 718 coating thicknesses of approximately $200 \mu \mathrm{m}$ on both Inconel 718 substrates and 316L stainless steel substrates. No increase in the rate of defects, which remained below $1 \%$ and were primarily oxide inclusions, was observed when using higher deposition rates. Voltage, capacitance, force, and travel speed collectively accounted for $80 \%$ of the variance observed in the deposition thickness.

4) The difference between a $\mathrm{Ni}$ - and Fe-based substrate was limited to the first $40 \mu \mathrm{m}$ of the deposit, in which a mixing zone with a composition and hardness between that of Inconel 718 and 316L stainless steel was formed. Outside of the 
mixing zone, the coating composition matched that of Inconel 718 and the substrate had no further influence on composition or properties of the coating regardless of thickness.

\section{References}

1. Donachie, M. J., and Donachie, S. J. 2002. Superalloys: A Technical Guide. ASM International.

2. Kumar, L. J., and Nair, C. G. K. 2017. Laser metal deposition repair applications for Inconel 718 alloy. Materials Today: Proceedings 4(10): 11068-11077.

3. Onuike, B., and Bandyopadhyay, A. 2019. Additive manufacturing in repair: Influence of processing parameters on properties of Inconel 718. Materials Letters 252: 256-259. DOI: 10.1016/j.matlet.2019.05.114

4. Petrat, T., Graf, B., Gumenyuk, A., and Rethmeier, M. 2016. Laser metal deposition as repair technology for a gas turbine burner made of Inconel 718. Physics Procedia 83: 761-768. DOI: 10.1016/j.phpro.2016.08.078

5. Lambarri, J., Leunda, J., García Navas, V., Soriano, C., and Sanz, C. 2013. Microstructural and tensile characterization of Inconel 718 laser coatings for aeronautic components. Optics and Lasers in Engineering 51(7): 813-821. DOI: 10.1016/j.optlaseng. 2013.01.011

6. Khan, M. S., Enrique, P., Song, G., Faria, M. I. S. T., and Zhou, Y. 2020. Laser-assisted wire cladding using a retrofitted laser welding system. Surface Engineering 37(5): 634-641. DOI: 10.1080/ 02670844.2020 .1820266

7. Ramesh, C. S., Devaraj, D. S., Keshavamurthy, R., and Sridhar B. R. 2011. Slurry erosive wear behaviour of thermally sprayed Inconel-718 coatings by APS process. Wear 271(9-10): 1365-1371. DOI: 10.1016/j.wear.2011.01.057

8. Singh, R., Schruefer, S., Wilson, S., Gibmeier, J., and Vassen, R. 2018. Influence of coating thickness on residual stress and adhesion-strength of cold-sprayed Inconel 718 coatings. Surface and Coatings Technology 350: 64-73. DOI: 10.1016/j.surfcoat.2018. 06.080

9. Ma, W., Xie, Y., Chen, C., Fukanuma, H., Wang, J., Ren, Z., and Huang, R. 2019. Microstructural and mechanical properties of high-performance Inconel 718 alloy by cold spraying. Journal of Alloys and Compounds 792: 456-467. DOI: 10.1016/j.jallcom.2019. 04.045

10. Stiglich, J., Campillo, B., Rosales, I., and Perez, R. 1999. Wear characteristics of WC-6Co coating deposited using pulsed electrode surfacing technique. Surface Engineering 15(4): 307-311. DOI: 10.1179/026708499101516650

11. Goodall, G., Kaplin, C., and Brochu, M. 2011. Autogenous electrospark deposition of NiCoCrAlY. Canadian Metallurgical Quarterly 50(2): 145-152. DOI: 10.1179/000844311X12949291727817

12. Liu, Y., Wang, D., Deng, C., Huo, L., Wang, L., and Fang, R. 2015. Study on fabrication of ceramic coatings on Ti-6Al-4V alloy by combined ultrasonic impact treatment and electrospark. Surface Engineering 31 (12): 892-897. DOI: 10.1179/1743294414Y. 0000000413

13. Gould, J. E., Ritzert, F. J., and Loewenthal, W. S. 2006. Preliminary investigations of joining technologies for attaching refractory metals to Ni-based superalloys. AIP Conference Proceedings 813: 757-765. DOI: 10.1063/1.2169257

14. Reynolds, J. L., Holdren, R. L., and Brown, L. E. 2003. Electrospark deposition. Advanced Materials \& Processes 161(3): 35-37.

15. Gould, J. 2011. Application of electro-spark deposition as a joining technology. Welding Journal 90(10): 191-s to 197-s.

16. Peterkin, S. 2016. Electro-spark deposition machine design, physical controls and parameter effects. Master's diss., University of Waterloo.
17. Tang, S. K., Nguyen, T. C., and Zhou, Y. 2010. Materials transfer in electro-spark deposition of $\mathrm{TiCp} / \mathrm{Ni}$ metal-matrix composite coating on Cu substrate. Welding Journal 89(8): 172-s to 180-s.

18. Enrique, P. D., Jiao, Z., and Zhou, N. Y. 2018. Effect of direct aging on heat-affected zone and tensile properties of electrosparkdeposited Alloy 718. Metallurgical and Materials Transactions A 50: 285-294. DOI: 10.1007/s11661-018-4997-1

19. Enrique, P. D., Jiao, Z., Zhou, N. Y., and Toyserkani, E. 2018 Dendritic coarsening model for rapid solidification of Ni-superalloy via electrospark deposition. Journal of Materials Processing Technology 258: 138-143. DOI: 10.1016/j.jmatprotec.2018.03.023

20. Enrique, P. D., Jiao, Z., Zhou, N. Y., and Toyserkani, E. 2018. Effect of microstructure on tensile properties of electrospark deposition repaired Ni-superalloy. Materials Science and Engineering A 729: 268-275. DOI: 10.1016/j.msea.2018.05.049

21. Reed, T. B. 1971. Free Energy of Formation of Binary Compounds: An Atlas of Charts for High-Temperature Chemical Calculations. Cambridge, Mass.: MIT Press.

22. Felix, L. M., Kwan, C. C. F., and Zhou, N. Y. 2019. The effect of pulse energy on the defects and microstructure of electro-sparkdeposited Inconel 718. Metallurgical and Materials Transactions A 50(9): 4223-4231. DOI: 10.1007/s11661-019-05332-8

23. Lešnjak, A., and Tušek, J. 2002. Processes and properties of deposits in electrospark deposition. Science and Technology of Welding and Joining 7(6): 391-396. DOI: 10.1179/136217102225006886

24. Kees, K. P. 1983. Hard-facing with electro-spark deposition. Final report. Washington State Univ. DOI: 10.2172/5537601

25. Frangini, S., and Masci, A. 2010. A study on the effect of a dynamic contact force control for improving electrospark coating properties. Surface and Coatings Technology 204(16-17):

2613-2623. DOI: 10.1016/j.surfcoat.2010.02.006

26. Wang, P. Z., Pan, G. S., Zhou, Y., Qu, J. X., and Shao, H. S. 1997. Accelerated electrospark deposition and the wear behavior of coatings. Journal of Materials Engineering and Performance 6(6): 780-784. DOI: 10.1007/s11665-997-0081-5

27. Belik, V. D., Litvin, R. V., Kovalchenko, M. S., and Rogozinskaya, A. A. 2007. Effect of pulse duration and size of interelectrode interval on electrospark spraying. II. Effect of pulse duration and size of interelectrode interval on composition and mechanical properties of coatings. Powder Metallurgy and Metal Ceramics 46(1-2): 95-99. DOI: 10.1007/s11106-007-0015-7

28. Belik, V. D., Litvin, R. V., and Kovalchenko, M. S. 2012. Effect of substrate temperature on the electrospark deposition, structure, and mechanical properties of coatings. I. Kinetics of substrate heating during electrospark deposition. Powder Metallurgy and Metal Ceramics 50(11-12): 698-703. DOI: 10.1007/s11106-012-9377-6

29. Vaidyanathan, S. 1970. Reducing wear of high-speed steel cutting tools by spark hardening. Wear 16(4): 255-260. DOI: 10.1016/0043-1648(70)90249-8

30. Vaidyanathan, S., and Venkatesh, V. C. 1974. Improving wear-resistance of high speed steel tools by carbide coating. Tribology 7(2): 54-58. DOI: 10.1016/0041-2678(74)90033-5

31. Enrique, P. D., Keshavarzkermani, A., Esmaeilizadeh, R., Peterkin, S., Jahed, H., Toyserkani, E., and Zhou, N. Y. 2020. Enhancing fatigue life of additive manufactured parts with electrospark deposition post-processing. Additive Manufacturing 36: 101526. DOI: 10.1016/j.addma.2020.101526

32. Kahlon, C. S., Baker, H. J., Noble, C. F., and Koenigsberger, F. 1970. Electric spark toughening of cutting tools and steel components. International Journal of Machine Tool Design and Research 10(1): 95-121. DOI: 10.1016/0020-7357(70)90028-4

PABLO D. ENRIQUE and NORMAN Y. ZHOU are with the University of Waterloo, Waterloo, Ontario, Canada. STEPHEN PETERKIN (speterkin@huysindustries.com) is with Huys Industries Ltd., Weston, Ontario, Canada. 